\title{
Isolation and Characterization of Antimicrobial Substance from Marine Streptomyces sp.
}

\author{
ROFIQ SUNARYANTO ${ }^{1,2 *}$, BAMBANG MARWOTO², TUN TEDJA IRAWADI', \\ ZAINAL ALIM MAS'UD ${ }^{3}$, AND LIESBETINI HARTOTO' \\ ${ }^{\prime}$ Department of Agro-Industrial Technology, Institut Pertanian Bogor, Darmaga Campus, Bogor 16680, Indonesia; \\ ${ }^{2}$ Center of Biotechnology, Balai Pengkajian dan Penerapan Teknologi, Kawasan Puspiptek, Serpong, \\ Tangerang Selatan, Banten 15314, Indonesia; ${ }^{3}$ Department of Chemistry, Institut Pertanian Bogor, \\ Darmaga Campus, Bogor 16680, Indonesia
}

\begin{abstract}
Isolation and purification of antimicrobial active substance produced by marine Actinomycetes has been carried out. Marine sediment samples were obtained from six different places at Banten West Coast. Isolation was conducted using two pretreatment methods, acid and heat shock pre-treatment. A total of 29 Actinomycetes isolates were obtained from the various sediment samples collected, then tested for antimicrobial activity against Escherichia coli ATCC 25922, Staphylococcus aureus ATCC25923, Pseudomonas aeruginosa ATCC27853, Bacillus subtilis ATCC 66923, Candida albicans BIOMCC00122, and Aspergillus niger BIOMCC00134. Among the isolates, isolate A11 was the most activity to Gram-positive and Gram-negative bacteria, and morphological observation and identification using 16S rRNA showed that the isolate was similar to Streptomyces sp. Production of active compound from A11 isolate used yeast peptone medium. Purification of active compounds was carried out using silica-gel-column chromatography and preparative HPLC. A single peak of active compounds was detected by HPLC, which showed a retention time of $8.35 \mathrm{~min}$ and maximum absorbance in UV visible at $210 \mathrm{~nm}$ and 274.5 nm respectively.
\end{abstract}

Key words: marine Actinomycetes, isolation, screening, antimicrobial activity, purification

Actinomycetes are the most widely distributed group of microorganisms in nature and which primarily inhabit the soil (Goodfellow and Williams 1983; Locci and Sharples 1983). Almost $70 \%$ of the world's antibiotics are known to come from Actinomycetes, mostly from the genera Streptomyces and Micromonospora (Berdy 2005; Fenical and Jensen 2006). In the past, researcher more focuses to explore the terrestrial Actinomycetes. Nevertheless, over time new antibiotics have been discovered from marine Actinomycetes (Fiedler et al. 2005; Lam 2006; Bull and Stach 2007).

Although the exploitation of marine Actinomycetes as a source to discover novel secondary metabolites is at an early stage, numerous novel metabolites have been isolated in the past few years. For examples, proximicin A, B, and C are novel antibiotic and anticancer compounds isolated from marine actinomycete Verrucosispora (Fiedler et al. 2008). Valinomycin, staurosporine, butenolide are anti-parasitic compounds from marine Streptomyces sp. (Elardo et al. 2010). Lodopyridone is cytotoxic to HCT-116 human colon cancer cells produced by a marine Saccharomonospora sp. (Maloney et al. 2009). L-glutaminase is enzyme therapy for cancer especially for acute lymphocytic leukemia produced by marine Streptomyces sp. (Balagurunathan et al. 2010). Abyssomicin $\mathrm{C}$ is a novel polycyclic polyketide antibiotic produced by a marine Verrucosispora strain (Riegdlinger $e t$ al. 2004), and possesses potent activity against Grampositive bacteria, including clinical isolates of multipleresistant strains. Diazepinomicin is a unique farnesylated dibenzodiazepinone produced by a Micromonospora strain (Charan et al. 2004) with antibacterial, anti-inflammatory and antitumor activities.

*Corresponding author, Phone/Fax: +62-21-7560208; E-mail : rofiqsn@yahoo.com
Indonesia is an archipelago country having a wide area of sea, which is more than 3.1 million $\mathrm{km}^{2}$. The characteristics of the sea showed a high level of biodiversity in microorganisms, plants, animals. Nevertheless this potential has not been exploited. Currently exploration of Actinomycetes in Indonesia is still limited to terrestrial Actinomycetes. The objective of this research were to isolate and to purify of active compounds produced by marine Actinomycetes such as A11 isolate.

\section{MATERIALS AND METHODS}

Sample Collection. Sediments were obtained from six marine sites in Banten West Java. From each location, six sediment samples of $5 \mathrm{~g}$ each were collected from $10^{-15} \mathrm{~cm}$ below the surface. Each of the sediment samples for each site was placed in small pre-labeled plastic bags and were tightly sealed. Hereinafter each sample was given code in accordance to sampling location.

Isolation of Actinomycetes. All sediment samples were processed in laboratory as soon as possible after collection. The samples were suspended in sterilized water and were made serial dilution. Pretreatment were conducted by using acid and heat-shock treatments. Acid treatment was conducted by the acidifying the samples to $\mathrm{pH} 2$ were obtained for $3 \mathrm{~h}$. Heat-shock treatment was conducted by the heating the samples at $60^{\circ} \mathrm{C}$ for $4 \mathrm{~h}$ (Pisano et al. 1986). Treated samples were then inoculated onto starch agar medium $(1 \% \mathrm{w} / \mathrm{v}$ starch, $0.4 \% \mathrm{w} / \mathrm{v}$ yeast extract, $0.2 \% \mathrm{w} / \mathrm{v}$ peptone, natural seawater, and $2 \% \mathrm{w} / \mathrm{v}$ agar) and incubated for 4-8 weeks at room temperature. One hundred gram per $\mathrm{mL}$ of nalidixic acid and $5 \mathrm{~g} \mathrm{~mL}^{-1}$ of rifampicin were added to reduce the number of unicellular bacteria (Pisano et al. 1989). The antifungal agent cycloheximide $\left(100 \mathrm{~g} \mathrm{~mL}^{-1}\right)$ and $25 \mathrm{~g} \mathrm{~mL}^{-1}$ nystatin were added to all isolation media. Actinomycetes colonies were recognized by the presence of 
branching, vegetative filaments and the formation of tough, leathery colonies that adhered to the agar surface. Morphologically diverse Actinomycetes were repeatedly transferred to the same media until pure cultures were obtained. All pure strains were grown in yeast extract-malt extract (YEME) broth and cryopreserved at $-80^{\circ} \mathrm{C}$ in $10 \%$ v/v glycerol solution.

Identification Based on 16S rRNA Analysis. The DNA was isolated using FastPrep kit for DNA isolation. The pellet was lysised using a lysing matrix, combined with 1 $\mathrm{mL}$, and homogenized using a FastPrep instrument for $40 \mathrm{sec}$ at $4500 \mathrm{rpm}$.

Polymerase chain reaction was done for DNA amplification using $8 \mathrm{~F}$ and $1492 \mathrm{R}$ primers. The PCR mixture containing $8 \mathrm{~F}$ and $1492 \mathrm{R}$ primers was added to the DNA solution. The PCR product was then purified using a Gel/DNA extraction kit.

The 16S rRNA gene obtained was submitted to the DNA sequencing facility, Genetic Laboratory, Biotech Centre. A big Dye ${ }^{\circledR}$ terminator V 3.1 cycle sequencing kit was used to sequence the DNA. The DNA was then run in an automated DNA sequencer using capillary electrophoresis (ABI 300 genetic analyzer). The sequence was compared to a database available at NCBI using the BLAST search engine.

Liquid Culture and Extraction of Active Substance. An established slant of isolate was inoculated into a $250 \mathrm{~mL}$ flask containing $100 \mathrm{~mL}$ of vegetative medium (YEME medium) consisting of : bacto peptone $5 \mathrm{~g} \mathrm{~L}^{-1}$, yeast extract 3 $\mathrm{g} \mathrm{L}^{-1}$, malt extract $3 \mathrm{~g} \mathrm{~L}^{-1}$, glucose $3 \mathrm{~g} \mathrm{~L}^{-1}$, demineral water 25 $\mathrm{mL}$, and sea water $75 \mathrm{~mL}$. $\mathrm{pH}$ value of the medium was adjusted to 7.6 before sterilization. The flask was incubated at $30^{\circ} \mathrm{C}$ for $2 \mathrm{~d}$ in an incubator-shaker. Fifty $\mathrm{mL}$ of the culture was transferred to $1000 \mathrm{~mL}$ of the fermentation medium. Fermentation medium consisted of bacto peptone $15 \mathrm{~g} \mathrm{~L}^{-1}$, yeast extract $3 \mathrm{~g} \mathrm{~L}^{-1}$, Fe (III) citrate hydrate $0.3 \mathrm{~g} \mathrm{~L}^{-1}$, demineralised water $250 \mathrm{~mL}$, and sea water $750 \mathrm{~mL}$ (Nedialkova and Mariana 2005). The $\mathrm{pH}$ value of the medium was adjusted to 7.6 before sterilization. The fermentation was carried out at $30^{\circ} \mathrm{C}$ for $5 \mathrm{~d}$ in incubator-shaker.

For extraction of active substance, the culture broth was centrifuged at $14000 \mathrm{x}$ g for $15 \mathrm{~min}$. The broth supernatants were divided and extracted using ethyl acetate as solvent. Supernatant and organic solvent were mixed thoroughly by shaking them in $1 \mathrm{~L}$ capacity separating funnel and allowed to stand for $30 \mathrm{~min}$. Two layers were separated; the aqueous layer and the organic layer, which contained the solvent and the antimicrobial agent. The organic layer was concentrated by evaporation under vacuum to the least possible volume, after dehydration with anhydrous $\mathrm{Na}_{2} \mathrm{SO}_{4}$. The aqueous layer was re-extracted and the organic layer added to the above organic layer. The organic layer was a concentrated by repeated cycle of evaporation under vacuum.

The dry extract of the supernatant was purified using silica gel column chromatography. Dry extract was injected onto the column and then eluted stepwise with chloroformmethanol solvent system as follows: First the column was eluted with $100 \%$ chloroform (Fraction 1). Then repeated with reducing the chloroform by $10 \%$ in each fraction while the methanol was increased by $10 \%$ in each fraction, until the percentage of methanol was $100 \%$. Thirty fractions were collected (each of $20 \mathrm{~mL}$ ) and then concentrated and dried for testing their antimicrobial activities. The active fractions obtained from chromatography column were further purified by preparative HPLC.

Preparative HPLC. Purification by preparative HPLC was conducted using a Waters 2695 HPLC, photodiode array detector (PAD), and Column puresil 5 C18 4.6x150 mm. The volume injected was $100 \mathrm{uL}$ per injection under conditions of average pressure of $1267 \mathrm{psi}$, and the flow rate was $1 \mathrm{~mL} \min ^{-1}$ where the mobile phase was $0-45 \%$ methanol-water and time period was $25 \mathrm{~min}$. (Kazakevich and Lobrutto 2007).

Antimicrobial Activity Assay. Antimicrobial activity was monitored by the agar diffusion paper-disc $(6 \mathrm{~mm})$ method. Discs were dripped with methanol solution of extract, dried and then placed over the agar surface plates freshly inoculated with either Escherichia coli ATCC 25922, Staphylococcus aureus ATCC25923, Bacillus subtilis ATCC 66923, Pseudomonas aeruginosa ATCC27853, Candida albicans BIOMCC00122, and Aspergillus niger BIOMCC00134 as test organisms. Suspensions of test organisms were adjusted to $10^{6} \mathrm{cfu} \mathrm{mL}^{-1}$. The most potent isolates were noted for each test microorganism, based on the mean diameter of inhibition zones (Bonev et al. 2008).

Analysis HPLC. Analysis was performed using HPLC with an analytical Sunfire C18 column $(4.6 \times 250 \mathrm{~mm}$, Shiseido Co. Ltd., Tokyo, Japan). Mobile phase used methanol-water (0-100\% linear gradient for $25 \mathrm{~min}$ and then isocratic elution with $100 \%$ methanol over $10 \mathrm{~min}$ ), at a flow rate of $1 \mathrm{~mL} \mathrm{~min}^{-1}$, volume of injection 10L per injection, and detection was at a of $210 \mathrm{~nm}$ (Kazakevich and Lobrutto 2007).

\section{RESULTS}

Isolation and Screening of Actinomycetes from Marine Samples. Twenty nine of actinomycete isolates were successfully isolated from 6 sediment samples. Eight of them showed antimicrobial activity, 2 isolates were active against $E$. coli ATCC 25922, 4 isolates were active against $S$. aureus ATCC25923, 2 isolates were active against $B$. subtilis ATCC 66923, 3 isolates were active against $P$. aeruginosa ATCC27853, 3 isolates were active against $C$. albicans

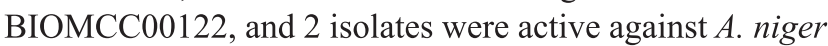
BIOMCC00134 (Table 1).

From 8 active isolates, A11 was chosen for further study due to highest activity against $\mathrm{Gram}^{-}$positive and Gramnegative bacteria. Identification using 16S rRNA revealed that isolate A11 was $100 \%$ homology to Streptomyces J22, class Actinobacteria, order Actinomycetales, family Streptomycetaceae and genus Streptomyces. Morphologically observation showed bold white color, glossy surface and circular with folding hyphae with some antenna (aerial hyphae) arising out in vertical. In the beginning of growth single globular colony was formed, and hereinafter the hyphae further expanded. 
The phylogenic tree (Fig 1) indicated that A11 has close contiguity with $S$. tanashiensis subsp. cephalomyceticus. An isolate of $S$. tanashiensis subsp. cephalomyceticus was recognized which could synthesize TAK-637 (tachykininreceptor-antagonist) (Tarui 2001).

Liquid Culture and Purification of Active Substance. Liquid culture of A11 was carried out for $5 \mathrm{~d}$ by using yeastpeptone medium. On the last day of culture, the medium color was darker and more viscous than on the first day. Many white granules were observed in the bottom of the flask. From a $5 \mathrm{~L}$ volume of culture we obtained $4.72 \mathrm{~g}$ of dry biomass was obtained and after extraction by methanol $2.72 \mathrm{~g}$ of extract was obtained. On the other hand, $0.33 \mathrm{~g}$ of ethyl acetate extract was obtained from supernatant. Antibacterial activity assay of the both extract against $B$. subtilis ATCC 66923 showed that the extract of supernatant

Table 1 Eight isolates of Actinomycetes (Banten West Java Coast) producing antimicrobial active

\begin{tabular}{|c|c|c|c|c|c|c|c|}
\hline \multirow[t]{2}{*}{ Isolate } & \multirow{2}{*}{$\begin{array}{l}\text { Sample } \\
\text { treatment }\end{array}$} & \multicolumn{6}{|c|}{ Diameter of inhibition (mm) } \\
\hline & & $\overline{\text { Escherichia coli }}$ & Staphylococcus aureus & Bacillus subtilis & Pseudomonas aeruginosa & Candida albicans & Aspergillus niger \\
\hline A64 & HS & - & - & - & - & - & 15.00 \\
\hline A610 & A & - & 12.00 & - & - & - & - \\
\hline A11 & HS & 18.00 & 15.00 & 14.00 & 14.00 & - & - \\
\hline A21 & HS & - & - & - & 7.00 & - & 9.00 \\
\hline A32 & HS & - & 12.00 & - & - & 7.00 & - \\
\hline A43 & A & 10.16 & - & 8.67 & 9.51 & - & - \\
\hline A44 & A & - & - & - & - & 10.61 & - \\
\hline A54 & HS & - & 8,56 & - & - & 8.67 & - \\
\hline $\begin{array}{l}\text { Positive control } \\
\text { rifamp icin } 500 \mathrm{ppm}\end{array}$ & & 23.52 & 9.16 & 15.98 & 15.18 & - & - \\
\hline nystatin $1000 \mathrm{ppm}$ & & - & - & - & - & 14.84 & 16.38 \\
\hline
\end{tabular}

HS, heat shock treatment; A, acid treatment; Diameter of paper disc $6 \mathrm{~mm}$

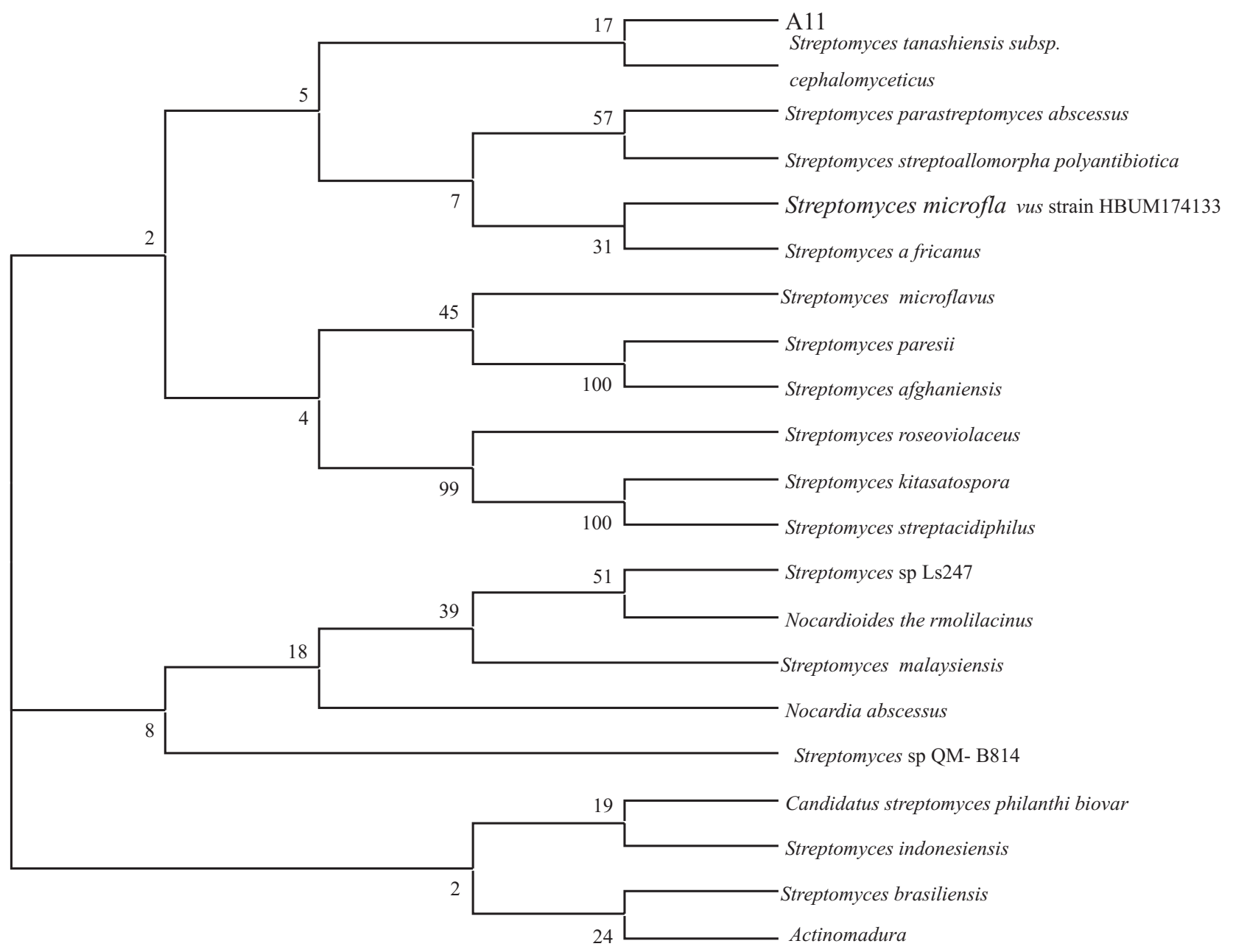

Fig 1 Polygenetic tree of isolate A11 shown as Streptomyces sp. 
was active, but no activity with the extract of biomass (Table 2). This was also confirm in HPLC chromatogram of both extracts, in where more peaks were in supernatant extract rather than in biomass extract (Figs 2 and 3).

Further purification of the supernatant extract was than carried out using silica gel column and preparative HPLC. As shown in Fig 4, several peaks were still observed in the chromatogram of HPLC preparative.

The antibacterial activity test applied to all fractions of HPLC showed that peak retention 10.1 min contained the active fraction. The fraction was then collected and used for HPLC analysis. Chromatogram of active fraction shows that active fraction had retention time of $8.623 \mathrm{~min}$ at gradient elution methanol-water $0-100 \%$ using analytical HPLC (Fig 5). Purification using preparative HPLC obtained a single peak with maximum absorbance of UV visible at $210 \mathrm{~nm}$ and $274.5 \mathrm{~nm}$ (Fig 6). This compound easy dissolves in methanol-chloroform $50 \%-50 \%$, but cannot dissolve in $100 \%$ chloroform.

\section{DISCUSSION}

We obtained six sediment samples derived from 29 isolates of Actinomycetes. Some of sediment samples obtained many isolate of Actinomycetes, but some of them did not contain Actinomycetes. It indicates that Actinomycetes are distributed unevenly in Banten, West Java Coast. When compared with brackish Actinomycetes, the population of marine Actinomycetes was less. Actinomycetes are less common in marine sediments relative to brackish environments (Goodfellow and Williams 1983; Parungao et al. 2007). Another study (Goodfellow and Haynes 1984) suggested that Actinomycetes represent only a small component of the total bacterial population in marine sediments. They observed that most of the isolates were of terrestrial and brackish origin. Terrestrial soils have been the main reservoir of Actinomycetes. They comprise a large part of the microbial population of the soil (Parungao et al. 2007). Table 1 shows that many Actinomycetes had antibacterial activity rather than anti fungal activity, same as reported by Berdy (2005). In the group of antibiotics, $66 \%$ are antibacterial (Gram-positive and Gram-negative), and 34\% are antifungi including yeast.

Selected isolate for further study (A11) which isolates showed high activity against Gram-positive and Gramnegative bacteria indicated that isolate was Streptomyces sp. Morphology of A11 is the same like genus of Streptomyces (Chater 2006; Antonova-Nikolova et al. 2007). Surface looked glossy and circular with folding hyphae that length and formed some antenna (aerial hyphae) arising out in vertical were characteristic of Streptomyces morphology

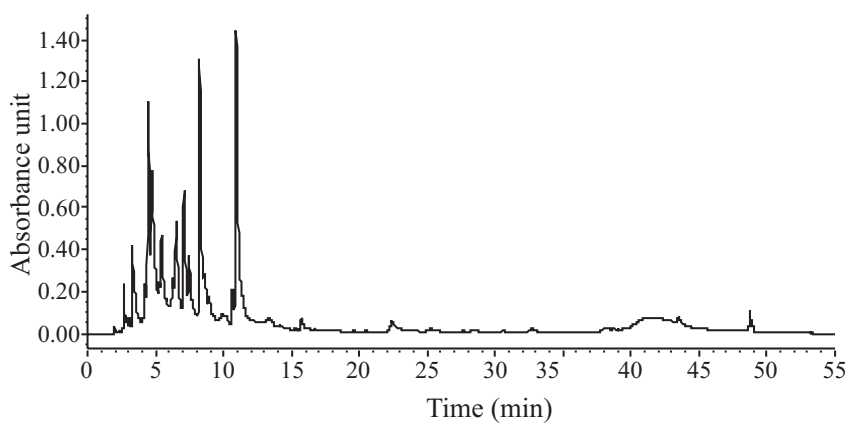

Fig 2 Analysis HPLC chromatogram of supernatant extract.

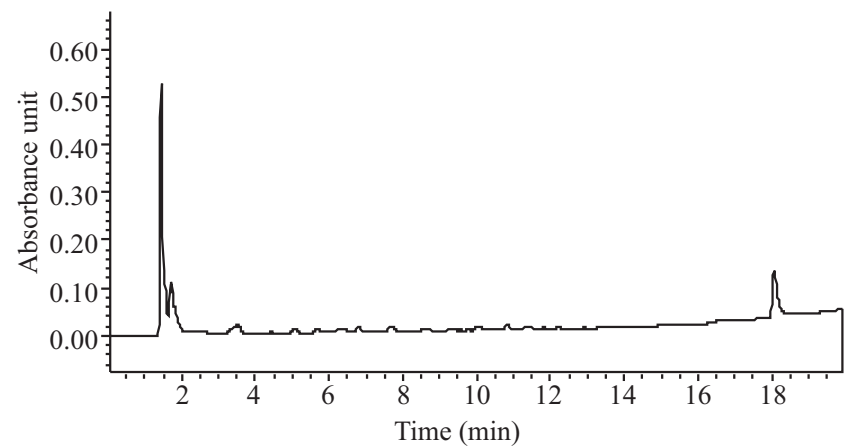

Fig 3 Analysis HPLC chromatogram of biomass extract.

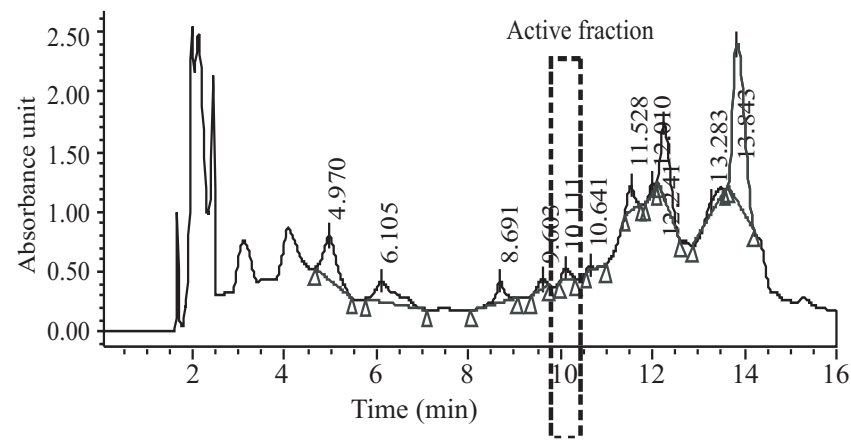

Fig 4 Chromatogram of preparative HPLC.

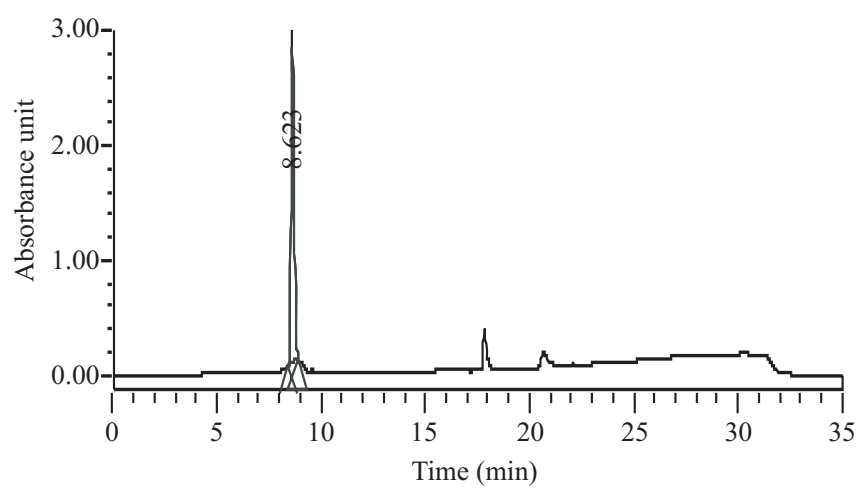

Fig 5 Analysis HPLC chromatogram of active fraction.

Table 2 Biological activity of biomass and supernatant extract from isolate A11

\begin{tabular}{|c|c|c|c|c|c|c|}
\hline \multirow[t]{2}{*}{ Sample } & \multicolumn{6}{|c|}{ Diameter of inhibition/clear zone (mm) } \\
\hline & lococcus aureus & Bacillus subtilis & Pseudomonas aeruginosa & Escherichia coli & Candida albicans & Aspergillus niger \\
\hline Biomass extract & - & - & - & - & - & - \\
\hline Supernatant extract & 10.39 & 24.43 & 9.64 & 9.55 & - & - \\
\hline Positive control (rifampicin 500 ppm) & 21.27 & 44.57 & 10.08 & 10.12 & - & - \\
\hline
\end{tabular}




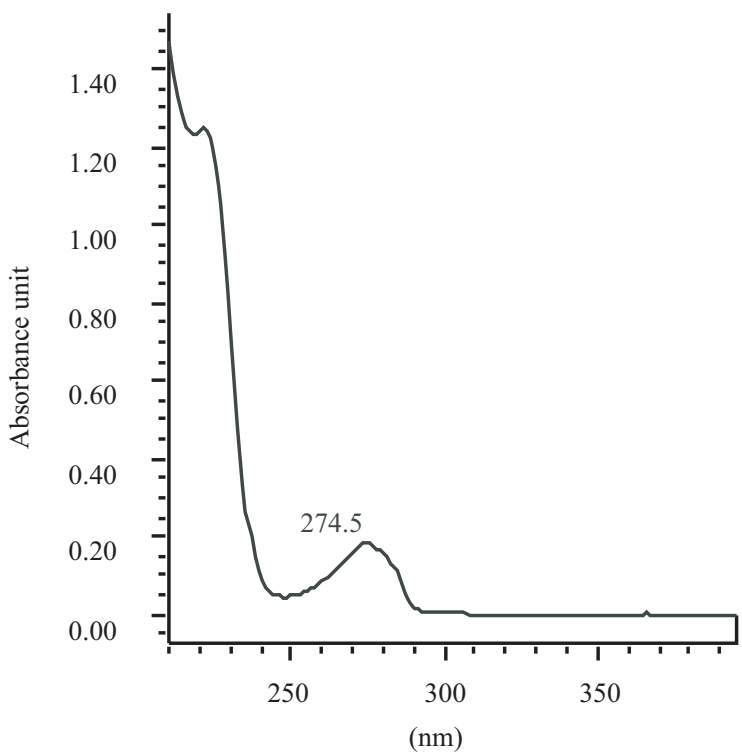

Fig 6 UV visible spectrum of active fraction.

(Flardh and Buttner 2009). Streptomyces are the one a genus of Actinomycetes that morphologically resemble fungi and physiologically resemble bacteria. Subsequent growth of Streptomyces colonies as they spread over the agar surface is thought to follow similar kinetics to filamentous fungi (Bushell 1988). The colony growth of the Streptomyces is initiated when a spore germinates, giving rise to one or more long multinucleoid filaments. These filaments elongate and branch repeatedly, originating a vegetative mycelium (substrate mycelium) that develops over, and into the culture medium (Miguelez et al. 1999).

Extract preparation of broth culture was carried out by using organic solvent. Table 2 showed that there were strong antibacterial activities on supernatant extract, but no in the biomass extract. This indicates that A11 produced antibacterial substance by extracellular secretion. The pattern of HPLC chromatogram (Fig 2 and 3 ) for supernatant extract and biomass extract in were different. Fig 2 showed many peaks, indicating that many compounds were produced by A11 and extractable from the supernatant. On the other hand, there were not many compounds showing up in extracts of the biomass (Fig 3). After further purification with silica gel column and preparative HPLC, the single active compound could be obtained. Fig 5 shows the polarity of active compounds, indicating semi polar and a high purity. UV maximum absorbance at $210 \mathrm{~nm}$ and 274.5 $\mathrm{nm}$ (Fig 6) indicated that this compound is colorless or white powder. It is reported that the most of peptide antibiotic exhibit maximum absorbance at 210-230 nm and 270-280 $\mathrm{nm}$. An absorbance at $220-230 \mathrm{~nm}$ is corresponding to characteristic absorption of peptide bonds (Kumar et al. 2009).

\section{ACKNOWLEDGEMENT}

We thank to Anis Mahsunah and Evita Chrisnayani for their valuable advice and support on this research. We also thank to Islamic Development Bank for supporting a scholarship.

\section{REFERENCES}

Antonova-Nikolova S, Stefanova V, Yocheva L. 2007. Taxonomic study of Streptomyces sp. strain 34-1. JCult Collect 5:10-15.

Balagurunathan R, Radhakrishnan M, Somasundaran ST. 2010. Lglutaminase producing Actinomycetes from marine sediments, selective isolation, semi quantitative assay and characterization of potential strain. Aust J Basic Appl Sci 5:698-705.

Berdy J. 2005. Bioactive microbial metabolites [review]. J Antibiot 58: 126.

Bonev B, James H, Judicael P. 2008. Principles of assessing bacterial susceptibility to antibiotics using the agar diffusion method. J Antimicrob Chemother 61:1295-301

Bull AT, Stach JEM. 2007. Marine actinobacteria: new opportunities for natural product search and discovery. Trends Microbiol 15:491-500.

Bushell ME. 1988. Growth, product formation and fermentation technology. In: Goodfellow M, Williams ST, Mordarski M, editors. 1988. Actinomycetes in biotechnology. London: Acad Pr.p 186-90

Charan RD, Schlingmann G, Janso J, Bernan V, Feng X, Carter GT. 2004. Diazepinomicin, a new antimicrobial alkaloid from marine Micromonospora sp. J Nat Prod 67:1431-33.

Chater K. 2006. Streptomyces inside-out: a new perspective on the bacteria that provide us with antibiotics. Phil Trans R Soc B 361:761-68.

Elardo SMP, Kozytska S, Bugni TS, Ireland CM. 2010. Anti-parasitic compounds from Streptomyces sp. Strains isolated from Mediterranean sponges. J Mar Drugs 8:373-80.

Fenical W and Jensen PR. 2006. Developing a new resource for drug discovery: marine actinomycete bacteria. J Nat Chem Biol 2:666-73.

Fiedler HP, Christina B, Alan TB, Alan CW, Michael G, Olivier P, Carsten P, Gerhard H. 2005. Marine Actinomycetes as a source of novel secondary metabolites. Antonie Leeuwenhock 87:37-42.

Fiedler HP, Bruntner C, Riedlinger J, Bull AT, Knutsen G, Goodfellow M, Jones A, Maldonado L, Pathom-aree W, Beil W, Schneider K, Keller S, Sussmuth RD. 2008. Proximicin A, B and C, novel aminofuran antibiotic and anticancer compounds isolated from marine strains of the actinomycete Verrucosispora. JAntibiot 61:158-63.

Flardh K, Buttner MJ. 2009. Streptomyces morphogenetics: dissecting differentiation in a filamentous bacterium. J Nat Rev Microbiol 7:3650 .

Goodfellow M, Williams ST. 1983. Ecology of Actinomycetes. Ann Rev Microbiol 37:189-216.

Goodfellow M, Haynes JA. 1984. Actinomycetes in marine sediment. In: Ortiz-ortiz L, Bojalil LF, Vakoleff V, editors. Biological, biochemical, and biomedical aspect of Actinomycetes. Orlando: Acad Pr. p 453-72.

Kazakevich. Y and Lobrutto R. 2007. HPLC for pharmaceutical scientists. New Jersey: John Wiley.

Kumar A, Saini P, Shrivastava JN. 2009. Production of antifungal antibiotic and biocontrol activity of Bacillus subtilis. Indian J Exp Biol 47:57-62.

Lam KM. 2006. Discovery of novel metabolites from marine Actinomycetes. Curr Opin Microbiol 9:24551.

Locci R, Sharples GP. 1983. Morphology of Actinomycetes. In Goodfellow M, Mordarski M, Williams S T, editors. The biology of the Actinomycetes. London: Acad Pr.p 165-99.

Maloney KN, MacMillan JB, Kauffman CA, Jensen PR, Dipasquale AG, Rheingold AL, and Fenical L. 2009. Lodopyridone, a structurally unprecedented alkaloid from a marine Actinomycete. Org Lett 23:5422-29.

Miguelez EM, Hardisson C, Manzanal MB. 1999. Hyphal death during colony development in Streptomyces antibioticus: morphological evidence for the existence of a process of cell deletion in a multicellular prokaryote. J Cell Biol $145: 515-25$.

Nedialkova D, Mariana N. 2005. Screening the antimicrobial activity of Actinomycetes strains isolated from Antartica. J Cult Collect 4:29-35.

Parungao MM, Maceda EBG, Villano MAV. 2007. Screening of antibioticproducing Actinomycetes from marine, brackish and terrestrial sediments of Samal Island, Philippines. JRes Sci Comp Eng 4:329-38.

Pisano MA, Michael JS, Madelyn ML. 1986. Application of pretreatments for the isolation of bioactive Actinomycetes from marine sediments. Appl Microbiol Biotechnol 25:285-88. 
Pisano MA, Sommer MJ, Brancaccio L. 1989. Isolation of bioactive Actinomycetes from marine sediments using rifampicin. Appl Microbiol Biotechnol 31:609-12.

Riegdlinger J, Reicke A, Zahner H, Krismer B, Bull AT, Maldanado LA, Ward AC, Goodfellow M, Bister B, Bischoff D. 2004. Abyssomicins, inhibitors of the para-aminobenzoic acid pathway produced by the marine Verrucosispora strain AB-18-032. JAntibiot 57:271-9.

Tarui N, Yoshinori I, Hideaki, Kazuo N. 2001. Microbial synthesis of three metabolites of a tachykinin receptor antagonist, TAK-637. Biosci Bioeng 92:285-7. 